\title{
The Perceived Value of a Universal Early Learning Program: A Parent Perspective
}

\author{
Jessie-Lee D. Mclsaac $\mathbb{(}^{1,2,3} \cdot$ Marla E. Smith ${ }^{1} \cdot$ Joan Turner $^{2} \cdot$ Christine McLean $^{2} \cdot$ Mary Jane Harkins ${ }^{3}$
}

Accepted: 12 December 2021 / Published online: 12 January 2022

(c) The Author(s) 2022

\begin{abstract}
Pan-Canadian efforts to support universal access to quality early childhood education and care (ECEC) for families are underway. Focusing on a universally available ECEC program in Nova Scotia, this study explored the impact of the perceived value of this publicly funded ECEC program on parental decisions for enrollment. A thematic analysis of data from focus groups and interviews ( $n=42$ families represented) from two separate, but related studies, revealed themes (Ease of access, Communication, Supporting familiarity with school and Early learning) which provide insight on the value that parents place on a universal ECEC program and may help to inform other jurisdictions.
\end{abstract}

Keywords Early childhood education $\cdot$ Universal child care programs $\cdot$ Public-funding $\cdot$ Parents

\section{Highlights}

- Explores the values families place on ECEC programs.

- Shares both experiences of those who did access the ECEC program and those who did not.

- Provides an opportunity to learn how to best meet parents needs and expectations while ensuring accessibility for all families.

The early years are recognized as a critical period for establishing the conditions for lifelong health and learning (Archambault et al., 2020, Ulferts et al., 2019). Ensuring access to quality early childhood education and care (ECEC) has shown positive benefits to children's development, especially for children in families experiencing socio-economic challenges (Magnuson \& Shager, 2010, McCain et al., 2007). Developing a supportive connection and trusting relationships between a child's home and early

Jessie-Lee D. McIsaac

jessie-lee.mcisaac@msvu.ca

1 Early Childhood Collaborative Research Centre, Mount Saint Vincent University, 166 Bedford Highway, Halifax, NS B3M 2J6, Canada

2 Department of Child and Youth Study, Mount Saint Vincent University, 166 Bedford Highway, Halifax, NS Canada, B3M 2J6 d Mount Saint Vincent University, 166 Bedford Highway, Halifax, NS B3M 2J6, Canada

3 Faculty of Education, Mount Saint Vincent University, 166 Bedford Highway, Halifax, NS B3M 2J6, Canada learning environment is an important component of quality ECEC programs (Barbarin et al., 2006, Lee \& Goh, 2012, Malsch et al., 2011). Parents may choose ECEC programs that align with their families' values as well as tangible and logistical needs, such as access to transportation services (Noble, 2007). Across Canada, some provinces/territories have been shifting from child care being viewed as solely a labor-market support toward a broader vision of ECEC as a public service to increased access to ECEC (Bennett, 2008, Savigny, 2017). Related policy initiatives in the country were introduced as early as 2004 but changes in government agendas have resulted in a somewhat staggered path leading toward subtle shifts over time (Akbari \& McCuaig, 2017). Developing a greater understanding of expressed values of parents is essential during the development of contextually relevant and inclusive ECEC programs. Furthermore, although previous research gives some insight into decisions related to accessing ECEC, there is limited research about the values the parents/guardians (hereafter parents) have placed on universal and publicly-funded early learning programs. In this research, we describe parents' perceived 
value of early learning within the context of a universal ECEC program in Nova Scotia (NS, Canada).

\section{Literature Review}

Enabling greater access to ECEC can provide a wide array of long-lasting developmental benefits for children (Melhuish et al., 2013, Siraj et al., 2016, Sylva et al., 2013) while also supporting broader benefits for families and communities (e.g., workforce participation, higher education, women in labor market) (Alexander et al., 2017). There are also other substantial societal benefits of supporting greater access to ECEC, such as enabling labor force participation and economic growth (MacDonald, 2018). Overlapping barriers related to ECEC access are predominantly a result of social structures, wherein social determinants of health such as income, education, and employment continue to lead to inequalities for children in general (Komro et al., 2014, Maggi et al., 2010). Although there is increased attention towards universal ECEC programs to address these inequities and systemic obstacles, access to regulated, affordable, quality early learning programs remains an issue for families in Canada.

\section{Barriers to ECEC}

The financial costs associated with accessing early learning and child care programs has been cited as a main barrier for Canadian families (Charlton et al., 2017, Lin \& Dunnett, 2018, Scotland, 2017). Although child care subsidies are often available, parents may be reluctant to interact with the provincial/territorial subsidy system due to the associated stigma, prior unpleasant experiences with other government assistance programs, difficulties applying to the program due to the required paperwork or lack of access to a reliable, secure computer (Lin \& Dunnett, 2018, Shlay et al., 2004). The application process may be especially concerning for low-income families, as it can require parents to take time off work to visit the government office, provide pay stubs or other income verification, and reapply (Shlay et al., 2004). Additional barriers to accessing ECEC may be organizational in nature, such as a lack of parental awareness of programs and services (Charlton et al., 2017, Graham \& Underwood, 2012), logistical challenges (Graham \& Underwood, 2012, Scotland, 2017), gaps in services such as the unequal supply-demand in care availability (Japel \& Friendly, 2019), or a lack of culturally relevant programming (Charlton et al., 2017, Graham \& Underwood, 2012, Kirova et al., 2013). For example, research has previously reported that the continued focus of Eurocentric curriculum and pedagogy continues to marginalize Indigenous knowledge, culture and languages in Canada (Eisazadeh et al.,
2017, Preston et al., 2012), suggesting that some programs and educators view differences in culture as a deficit rather than an asset in early education settings (Kirova, 2013). Culturally relevant programming in early childhood is essential to meet the needs of all children, especially as there is often a cultural imbalance between educators (often White, middle-class, monolingual women) and the population of children (Allen et al., 2017, Saluja et al., 2002).

\section{Parental Preferences for ECEC}

The preferences that families hold related to ECEC also influence their decisions to access programs. A recent national survey in Canada that explored parental decisionmaking for child care arrangements found the location of the service provider as the most frequently reported reason for choosing a particular service, followed by service provider-characteristics, hours of operation, and cost (Statistics Canada, 2019). Preference for the location of care providers has been emphasized in the literature and is likely of particular concern for rural or remote families (Graham \& Underwood, 2012). Further, ECEC typically operates during traditional business hours which can be unsuitable for some families and may result in a 'patchwork' of care, where children are shuffled between multiple service providers per day to accommodate parents' working hours (Graham \& Underwood, 2012, Japel \& Friendly, 2019). Despite the concerns related to access, parents have reported various positive impacts of ECEC on their child, including social and language development and opportunities for outdoor play (Sackes, 2013, Singh \& Zhang, 2018). Additionally, parents have expressed appreciation for programs that valued differing cultural backgrounds and supported their children with identified, diverse needs (Blackmore et al., 2016, Underwood \& Killoran, 2012). Families who differ in socioeconomic status, language, and ethnicity may have different views of early childhood program quality (Barbarin et al., 2006). For example, providing space within education systems for Indigenous languages and culture (i.e., through dramatic play) provides both children and parents with a connection to their ancestral roots (Battiste, 2008, Peterson \& Horton, 2019). More attention is needed to ensure inclusive and culturally responsive environments for all children in ECEC programs.

\section{Program Quality}

The definition of quality in early childhood programs is not straightforward, with some theorists describing it as a predominantly socially constructed concept and firmly embedded in tradition and logical positivism (Dahlberg et al., 2013). A commonly used definition of high-quality ECEC programs focus on both process (engaging materials 
and activities, positive interactions between adult and child) and structural components (e.g., staff qualifications, and adult-child ratio) (Bigras et al., 2010). Research suggests that parents often value the emphasis on positive relationships (element of process quality) between educators, children and families (Noble, 2007, Scopelliti \& Musatti, 2013, Sollars, 2020) and also have an appreciation for tangible and observable components that encompass the physical and structural aspects of ECEC programs (Sollars, 2020). Studies have also suggested that parents appreciate new experiences for their children, opportunities to build independence, support for social and emotional development and academic learning for their children (Matei \& Ghenta, 2018, Noble, 2007, Scopelliti \& Musatti, 2013). Providing a safe and trusting environment, offering guidance, and listening to families' suggestions regarding their child's education have also been suggested as reasons that a parent would access a ECEC program (Matei \& Ghenta, 2018, Noble, 2007).

\section{Research Context}

In the small east coast province of Nova Scotia (NS, Canada), children are particularly vulnerable to increased rates of poverty and the related impacts on their overall development (Frank \& Fisher, 2020). To support families with young children in NS, the provincial government launched a universal early learning program called the Preprimary Program in 2017. This publicly-funded (no-fee), play-based learning program is available to children in the catchment area of their school community in the year prior to formal school entry (children must be four-years old before the end of the calendar year to enroll) and offers similar hours to a regular school day (i.e., 8:30 am-2:30 pm). Pre-primary Programs are located in schools and operated by Regional Centers for Education and the Francophone school board under the auspices of the provincial government through the NS Department of Education and Early Childhood Development (Nova Scotia Department of Education and Early Child Development, 2017). Programs started to be implemented in 2017-18, with full implementation in all school communities achieved in September 2020.

The Pre-primary Program is led by early childhood educators and has adopted a play-based learning approach that is child-led and child-initiated and encompasses many different types of play, such as socio-dramatic play, active play, pretend or fantasy play, and rough and tumble play (Department of Education and Early Childhood Development, 2018). This program is both voluntary and universal (available to any eligible child with no-fee to parents) and aims to increase access to early learning opportunities for children throughout the province. Given the importance of understanding the expressed values of parents to develop contextually relevant and inclusive ECEC programs, our study sought to elucidate parental needs and expectations of this universal program early in its implementation in NS. Our findings were expected to provide transferable information for other jurisdictions undergoing similar universal efforts in ECEC programs to ensure accessibility for all children.

\section{Methods}

\section{Theoretical Framework}

A social constructivist framework was used in our research which reflects the belief in the co-construction of knowledge through interactions with people and their environment (Dodd-Nufrio, 2011). This approach recognizes and acknowledges that the perceived value parents place on ECEC programs is largely influenced by their prior personal experiences and interactions (Amineh \& Asl, 2015, DoddNufrio, 2011). When applying this understanding to our research, it meant that we accepted and understood that parents' perceived values were developed through experiences and interactions with their own school experiences, their ability to access various informal or formal child care arrangements, including programs designed as 'preschools' as well as their own direct or indirect involvement with the recently introduced Pre-primary Program (Dodd-Nufrio, 2011).

\section{Research Design}

Our research study was designed to better understand the values of parents and to deepen our understanding of parental decisions to access the program through their child's enrollment. Our study includes parents (legal guardians) of children who did attend the Pre-primary Program and parents of children who did not enroll in the program. To achieve this goal, our research brings together two separate, but related studies conducted as part of a larger program of research that is exploring early childhood policy initiatives across Nova Scotia. The thematic analysis process described by Braun and Clarke (2006) was used as a guide for each of our research studies. Additionally, in both projects, we used a Qualitative Description (QD) approach to gather the perceptions of parent participants. We felt the QD approach was appropriate for the exploratory nature of our study and reinforced the importance of the lived experiences of the participants viewed from our social constructivist framework (Neergaard et al., 2009, Sandelowski, 2009). Further, this methodology was ideal for our study because 
the QD analytical process and presentation of data allowed us to remain close to the data in each study and describe participant experience through their direct experiences of the interactions and events (Milne \& Oberle, 2005, Neergaard et al., 2009). Data collection across our two studies are described hereafter.

\section{Data Collection: Study 1}

We purposely selected four Pre-primary Program sites in different regions to represent different program and community characteristics (e.g., existing/new program, rural/ urban, Francophone/Anglophone) in the first year of implementation (2017-18). Parents that were already participating in these programs were invited to take part in a focus group with the assistance of those involved with the programs. Focus groups $(n=4)$ were 30-60 minutes and conducted at the location of the Pre-primary Program using a semistructured guide to understand participants' perceptions and perceived value of the program. During the focus groups, we asked parents questions regarding their experiences with the Pre-primary Program. Specific questions included accessing the Pre-primary Program, day-to-day routines inside the program, relationships with educators and suggestions on what could make the program better to support themselves and their children. Interview questions were reviewed by different members of our research team prior to data collection.

\section{Data Collection: Study 2}

We selected seven communities across Nova Scotia to represent diverse communities across the province in the second year of the implementation of the Pre-primary Program (2018-19). Our study aimed to access the parents of children who did attend the Pre-primary Program and parents of eligible children who did not enroll. We made initial contact within communities to assist with the community recruitment (e.g., resource centers and local community organizations). Recruitment posters and handouts for parents were distributed based on the recommendations from community partners. Once parents expressed interest, a date, time and location for a focus group or telephone interview was organized based on the preference of families. Focus groups $(n=3)$ and interview $(n=1)$ were 30-60 minutes where our research team used a semistructured interview guide to describe families' experiences with the Pre-primary Program, their motivations for participation (or nonparticipation) and their needs for other supports for early childhood development. During the focus groups and/or interview, we used probes, such as, "could you tell me more about your experience", and/or "what do you mean by that", to identify issues related to access to
Table 1 Participant and community demographics

\begin{tabular}{lll}
\hline & Community demographics & $\begin{array}{l}\text { Number of } \\
\text { families }\end{array}$ \\
\hline Study 1 & Rural village & 4 \\
& Rural village & 7 \\
& Rural town & 9 \\
& Inner-city community & 8 \\
& Total: 28 & \\
Study 2 & Inner-city community—newcomer & 9 \\
& population & \\
& Rural town & 2 \\
& Rural town & 2 \\
& Rural village - minority underserved & 1 \\
& community & \\
& Total: 14
\end{tabular}

All communities were distinct; rural village refers to a community outside of towns and cities that are smaller than a town with a population ranging from a few hundred to a few thousand people. Rural towns refer to an area that is slightly larger than a rural village, but smaller than an urban city, consisting of over a few thousand people. Inner-city community refers to urban areas that are highly populated and have access to transportation, etc.

programs and services. We also asked for participant recommendations for changes to policy and practice, therefore, assisting in identifying opportunities to better support families in their communities. Interview questions were reviewed by multiple members of our research team prior to data collection.

\section{Data Analysis: Both Studies}

In Study 1, 28 families of children that attended Pre-primary Program sites took part in four focus groups. In Study 2, there were 14 families that took part in three focus groups and one interview (see Table 1). Across both studies there were one or two parents that participated in our study to represent their family. Audio-recordings from the focus groups and one interview were transcribed verbatim, data was de-identified, and then, along with field notes, was imported into a qualitative software for analysis (QSR NVivo Version 12). If participants were not comfortable with being audio recorded, detailed notes were documented from participant responses. A thematic analysis process was used to guide the analysis and support our QD approach to portray the participants' individual and unique experiences. In both studies, data were reviewed and initial codes were created in a codebook and at least two members of the research team participated to support a rigorous and trustworthy coding process. Following the coding process, we began searching for broader level themes, based on larger ideas of the initial codes. These themes were viewed to explore the perceived value of the Pre-primary 
Program from the perspective of parents who had accessed the program and families that did not. Our team reviewed and refined the final list of themes to inform the purpose of our study using a QD approach. Interpreting various perspectives allowed for the discovery of common themes, moving beyond what the participant reported, and clustering together common ideas from multiple individuals to represent the data (Braun \& Clarke, 2006, Willis et al., 2016). These commonalities across our two studies are further explained throughout four distinct themes. The use of participant quotes provides an important QD narrative to respond to our study purpose (Braun \& Clarke, 2006). The unique results of each study are presented below followed by a discussion on the overall perceived value of the universal Pre-primary Program (Table 2).

\section{Study 1 Results}

Four themes were identified in our first study that provide insight into the value that parents placed on the Pre-primary Program: Ease of access, Communication, Supporting familiarity with school, and Early learning. First, participants spoke about the importance of supports to ensure they could easily access the program, stating that they felt it was valuable that the program was available to all families in their school community. Many participants described the program as providing a financial relief as they no longer had to pay for regulated child care. For example, one participant said, "to be honest, quite frankly, it was financial. My kids had to be in daycare five days a week and it [Pre-primary Program] was a heck of a lot cheaper". Others explained that they were unable to afford child care prior to the introduction of the Pre-primary Program and this provided their child the first opportunity to participate in a formal early childhood program at no-fee to the family. Transportation and before and after care were provided at only one of the Pre-primary Program sites in this study and parents from this particular site voiced how valuable transportation was to accommodate working parents. Participants who attended sites without this service outlined concerns surrounding transportation to and from the Preprimary Program and expressed a desire for their child(ren) to be able to use the bus. One participant stated:

"Transportation has been an issue for us at times throughout the program, and it would be nice if the children would have the same opportunity to travel on the school bus to and from the school, as other children in similar programs are able to do. Also, if the transportation issue is unable to be fixed, an extended day or a program they could attend afterwards at the school would be helpful for those 
of us who work until $5 \mathrm{pm}$ and have to find a way to have our children picked up by 2 pm".

In some cases, lack of bus access was identified as a barrier to attending the Pre-primary Program every day. This also related to the value of ensuring easy access to the program as some parents noted the importance of available before and after school programming to accommodate work schedules.

Participants who accessed the program also described how they valued communication with Pre-primary Program early childhood educators. Parents valued being informed about their child's day and appreciated communication with staff in the program. One participant spoke about their relationship with educators:

"We have a great relationship with the Pre-primary educators they always keep us informed about how his day went and tell us what adventures they went on or what he learned about that day. They have always made us feel like we could communicate with them from the beginning and straight through the program".

Although many participants expressed a favorable view of their communication with early childhood educators, some did express a desire for more communication. Some indicated that they would like to know more about what their child was doing on a daily basis at the Pre-primary Program, and that they struggled to get this information because early childhood educators were often too busy during pickup and drop-off times. An additional concern surrounding communication became apparent at one of the sites where access beyond the front entrance of the school was restricted due to security protocols from school administration. This meant that parents were unable to enter or visit the classroom and observe the activities that their child was doing and speak to the educators. As stated by one participant:

\footnotetext{
"Because the way the school is set up, the children arrive and they [early childhood educators] greet them at the door so we [parents] aren't walking them to the classroom. So that's a change for parents who are used to going to pre-school or daycare with their child. So that kind of has, limited the communication a bit'.
}

Participants indicated that they valued the focus on early learning in the Pre-primary Programs. Parents valued the increased opportunity for their children to learn new skills that they may not have been exposed to outside of the program. For example, participants described enhanced social-emotional (i.e., social skills, coping strategies) and language development, as well as increases in children's confidence, since their child's enrollment in the Pre-primary Program. There was also discussion among participants during the focus groups about ways they value the play-based philosophy of the Pre-primary Program. One participant spoke about their perspective on the focus on play:

"Yeah 'cause I know say-I've heard other parents say well where it is play-based I don't feel like my child would benefit from it because they you know already knew all that kind of stuff but it's so much more than when you think of play-based it's not just playing ya know? They learn so much..."

However, while many appreciated the focus on play, others expressed concern that it is not academically oriented or structured enough to fully support children's development and their transition to Grade Primary, for example: "...I ask her [child in program] everyday "what did you learn today" nothing, right? The structure is not there...I can see that starting out but they should be able to gradually start bringing in some structure in there".

Throughout the focus group discussions, participants described the ability of the Pre-primary Program to support familiarity with the school environment. Many expressed that they thought their child would be better prepared and that the transition into Grade Primary would be easier as a result of attending the Pre-primary Program, for example:

"Really the whole point of Pre-primary they're coming and they're-they're getting a taste of what schools going to be. So, they're already getting the location they know where the cafeteria's gonna be, they know how to sit in the cafeteria, and it helps the staff out'.

Participants also expressed the importance of the program in making connections with other teachers, classrooms and programs within the school environment. We observed this connectedness in three of the four Pre-primary Program sites where early childhood educators were engaged and included in school-wide events and the Pre-primary children were provided with opportunities to utilize school spaces other than their classroom. This connection was not evident in the fourth site, with some participants describing how the Pre-primary Program felt separate from the rest of the school. As one participant stated: “...our guys [children in Pre-primary] have never really been invited to any of these things that are happening school-wide... maybe they're thinking they're too young and they're reasons for that, but it's also you know, being included..." 


\section{Study 2 Results}

In our second study, we selected seven communities across Nova Scotia to represent diverse regions across the province. Most of the participants (13 out of 14) did not register their child in the Pre-primary Program, which allowed further identification of factors that might influence access to the program. Consistent, with our first study, participants similarly expressed the importance of easy access to the Pre-primary Program. Participants placed value on the fact that the program was available at no-fee to parents, which they felt provided an opportunity to support families who could not afford child care. For example, one particular family chose to enroll their child into the program because they could not afford child care fees:

"We moved out to Nova Scotia and we were once
again in a position where I couldn't pay for preschool
so we went looking for a library programs and other
things that I could get my daughter into 'cause she
was going to be into that—-that age group and then I
got the emails about signing up for Pre-primary and
I'm like "okay sure!" Full-expecting it not to be a
full day five days a week and yet when I got there to
sign up its full day five days a week I'm like "really?
At Pre-primary? Okay?" and so we jumped in with
two feet and just she loved it. Absolutely adored it".

Similar to Study 1, many participants stated that the program did not match their work schedules due to the lack of before and after care and also expressed difficulties with transportation. In one instance, a participant specifically expressed that they did not have access to a personal vehicle and felt that walking their children to Pre-primary in the winter would be difficult. Another participant noted: "It's hard with the transportation because, a lot of people just can't get their kids there... with their schedules... so it cuts down a lot of the attendance".

Participants in our second study also valued communication in relation to the Pre-primary Program, however, in this case, the communication centered on general information on the program rather than between parents and educators in Study 1. Participants expressed interest in the program but had limited interaction with those directly involved; often their understanding of the program was the result of conversations with other community members. Many participants did not have first-hand knowledge on the program and were uncertain about what the Pre-primary Program offered. One participant also indicated that they had difficulty finding out information about the program at the school: "....when I went to check out the program...and talked to the principal about the qualifications of the people [educators in the program]... and the principal actually did not know". Another participant thought enrollment in the Pre-primary Program was similar to school, presuming that daily attendance was mandatory. Language barriers also seemed to present a barrier to newcomer families. One participant indicated that clear and helpful information should be made available through consistent translation of program documents (e.g., newsletters and information sheets) to ensure all families could read the information. As stated by this participant through an interpreter in the focus group:

"There needs to be a larger emphasis on understanding and getting people from this population [newcomers] involved. They [parents] are suffering from the paperwork from the school as well when enrolling their children into programs. Maybe we can have them translated beforehand so that families can get a bit of an understanding, what they send home isn't clear and having these documents translated would help. There's a big language problem there".

Compared to Study 1, most participants in Study 2 were less familiar with how the program might help children become familiar with the school environment. This was likely a result of the fact that the majority had not registered their child in the program and did not have a lot of information about the program. Those more familiar with the program in Study 2 discussed how they thought re-primary would help their child learn about school settings, including the expected rules, and prepare them for academic skills such as reading and writing. For example, one participant said:

“...if they go to Pre-primary...instead of sitting with mum and sitting every time at home if we go in the school they [learn] how to read how to write something they need-they [learn] many things...the rule of the school they know, because of that...it's very important for kids,"

Another participant decided not to enroll their child to spend more quality time together in the year before school and reflected upon how it might have helped their child become more familiar: "I mean it probably would help with that transition and comfort level piece...Maybe it was just me who wasn't ready!"

Finally, participants spoke to the early learning aspects of the program and reported that if their children attended the program, they felt learn language and social skills. In particular, newcomer participants discussed the possibilities of supporting language as many of their children were learning English. One participant specifically indicated the 
possibilities for their child to learn English through their interactions with educators and other children:

"Pre-primary, they go there, they share with different kids they talk each other... In my home I talk with my language because even me I don't know English perfect, I talk with my language. They don't know anything, they listen only cartoon and that is not enough. If you go Pre-primary program that is very good for kids to prepare for Primary..."

Participants also spoke about the Pre-primary Program as being an opportunity for their children to socialize and make new friends. One participant in Study 2, whose child attended the program, stated that their daughter made new friends in Pre-primary, which was helpful as they had just moved to the province. Another participant expressed that although socialization was important, they would have liked more structure in the program. As stated by this participant: "I almost feel like it's more for socialization than for learning, but I have a huge family so my daughter socializes often and-and I think socialization is important, but I would like to see more structure". Similar to Study 1, while some participants valued play-based learning, others were unsure why the program was focused on play rather than more structured academic learning experiences.

\section{Discussion}

The aim of our research was to describe parents' perceived value of the publicly funded, no-fee, play-based Pre-primary Program across Nova Scotia through integrating the results of our two studies. Parent participants described the value of Pre-primary Programs in terms of its ease of access (no-fee and available within each school catchment area); its potential to ease the transition to school for young children by supporting familiarity to the school and its routines; its focus on early learning; and its ability to inform parents about the value of play-based programming by providing information about their child's activities and progress through well-developed communication between educator and parent. In addition to the defined value of these programs, participants also noted challenges and barriers associated with the Pre-primary Program. To increase access to the program, many parent participants spoke of the need for additional supports such as before and after care and transportation. Although all valued the early learning focus on social skills, they held different perspectives on the play-based nature of the program, with some expressing a desire for more structured academic learning.

Critically important to universal ECEC programs is ensuring that all parents can access this support. First, the availability of the program in local communities is important considering the existence of gaps across Canada (MacDonald, 2018). The Pre-primary Program is now available in all school communities, however, at the time of our study, three out of 14 participants in Study 2 said that the Pre-primary Program was not offered in their catchment area. The cost of ECEC is a commonly cited obstacle that prevents access to programs (MacDonald, 2018, Statistics Canada, 2019), which has been partially addressed by the no-fee component of the program. Parents in our study also expressed value for additional supports including the accommodation of additional hours for working parents and logistical supports such as transportation. Program hours is discussed in the literature regarding barriers to accessing child care in Canada, especially for rural or remote parents (Graham \& Underwood, 2012) and parents who work nonstandard hours (Japel \& Friendly, 2019). It is clear that a comprehensive approach is needed to consider the full scope of needs for parents to ensure that universal ECEC programs are truly accessible for all (Campbell et al., 2019). This can be achieved by adding relevant service components to existing structures (Pelletier \& Corter, 2005).

Parents in both of our studies discussed the importance of communication in relation to the Pre-primary Program. Previous literature reinforces the importance of a positive relationship between educators and families, which is a well established component of process quality in ECEC programs (Masten et al., 2009, Sollars, 2020). Communication between educators and parents can create positive relationships that both create and enhance an educator's ability to provide general information to the family, such as classroom expectations and discussions concerning the needs of the child (Masten et al., 2009). Direct involvement and participation in their children's learning environments can create a feeling of appreciation and support for parents' own challenges and needs (Sollars, 2020). Further, parents who feel welcomed and accepted in ECEC programs and feel that their input and perspectives are valued are more likely to become involved, which can facilitate a seamless program transition into the school system for both children and parents (Masten et al., 2009, Sollars, 2020). Parent involvement can also promote communication with teachers and a higher level of trust and positive regard for the educators in the school system (Lee \& Goh, 2012, Malsch et al., 2011).

Supporting children's familiarity with the school environment was another noted value of parents in both of our studies, which is a unique element of this ECEC program given its placement within schools. Locating the Pre-primary Program within schools in Nova Scotia provided a link to the public-school system that is mandated 
to provide education and information to young children and their families. The transition into school settings is marked with many changes for children and can set the foundation for future academic success and for children and families' relationships with the education system. Previous research emphasizes the importance of family involvement, linkages, close coordination and continuity between early childhood programs and primary schools (Lee \& Goh, 2012, Malsch et al., 2011). Earlier connections to the school through ECEC programs has been explored in other initiatives in Canada through broader integrated service delivery models (Corter \& Pelletier, 2010, Pelletier \& Corter, 2005) but further research is needed to understand how the placement of distinct ECEC programs in schools supports children's development over time.

Parent participants also spoke to the perceived value of the program in terms of a child's learning and development, particularly skills such as socialization and language acquisition, which were viewed by parents to support their child's transition into school. Although parents spoke to the benefits of using a play-based approach, they also spoke to their reservations regarding this focus on play, with some stating that they wished the program was more structured. As stated previously, parents can have multiple ideas of what quality early childhood education means (Sollars, 2020). While parents have insights into what they believe is quality care in the early years, as their children develop, they are keen to ensure that they are prepared for formal schooling (Sollars, 2017). It seems that more dialog is needed between educators and parents concerning the nature of the program and the value of play and its influence on children's learning (Sollars, 2017). Although play-based learning was viewed by some parents as being unstructured and less academic than explicit instruction; play-based learning has been shown to be as or more effective than traditional direct-instruction for achieving literacy, numeracy, and socioemotional early learning classroom goals (Fisher et al., 2013, Stipek et al., 1998, Weisberg et al., 2013). Further studies have suggested that some parents only value play if it does not interfere with learning academic skills (Baker, 2014, Kane, 2016, Yahya, 2016). Parental perspectives appear to be influenced by a number of factors, and previous research on the Pre-primary Program has found that positive views on play may be influenced by parents' connection to the school community and communication with a child's educators (Carolan et al., 2019). The varied family perspectives on play-based learning in our study and other ECEC programs highlights the importance of further research to study the ways to further understand and learn more about the concerns of parents and ways to work together to ensure high quality, play-based ECEC programs.

\section{Conclusions}

Ensuring families have access to ECEC programs is necessary for achieving a range of public goals, including closing the gender wage gap in the economy, spurring economic growth, easing the burden on struggling parents and supporting healthy child development (MacDonald, 2018). Our study provides perspective on the values that parents place on an ECEC program that is in early stages of implementation and it provides an opportunity to consider how to best meet parental needs and expectations while ensuring accessibility for all children. The intent of the research was not to generalize the experiences of families but rather provide an exploration of possible parental values of universal ECEC programs through integrating the results of two qualitative studies. We provided contextual information on the Pre-primary Program information to inform the transferability to similar system-wide efforts to improve access to ECEC programs. Our work builds on previous research on this initiative in Nova Scotia by reinforcing the importance of communication with families about the program, including the importance of play-based learning within ECEC programs (Carolan et al., 2019). Because the Pre-primary Program is located in school settings, it also provides a unique contribution to the literature of the value that parents have on the location of the program and how this characteristic supports children's familiarity with school programs. Overall, our research may help to inform other jurisdictions that are shifting toward a broader vision of early childhood education as a public service. Moving forward, future studies should explore how the values of parents are understood and incorporated in the development of contextually relevant, and culturally responsive, ECEC programs.

Acknowledgements The authors would like to thank all parents that participated in both studies. We would also like to acknowledge support from all community and Pre-primary Program partners for helping to promote participation with parents.

Author Contributions All authors contributed to the study conception and design. Material preparation, data collection and analysis were performed by J.L.D.M., M.E.S., J.T. and C.M. The first draft of the manuscript was written by J.L.D.M. and M.E.S. and all authors commented on previous versions of the manuscript. All authors read and approved the final manuscript.

Funding Study 1 was supported by the Margaret and Wallace McCain Family Foundation in partnership with the Nova Scotia Department of Education and Early Childhood Development. Study 2 was funded by the Nova Scotia Department of Education and Early Childhood Development through the Inter-University Research Network. This research was also undertaken, in part, thanks to funding from the Canada Research Chairs program.

\section{Compliance with Ethical Standards}

Conflict of Interest The authors declare no competing interests. 
Ethical Approval All procedures performed in both studies were approved and in accordance with the ethical standards of the University Research Ethics Board at Mount Saint Vincent University.

Consent to Participate In study 1 , informed consent was obtained from all individual participants included in the study. In study 2, verbal consent was obtained from all individual participants included in the evaluation

Consent to Publish In study 1 , written permission to use their experiences for future reports and publications was obtained from all participants. In study 2, verbal permission to use their experiences for future reports and publications was obtained from all participants.

Publisher's note Springer Nature remains neutral with regard to jurisdictional claims in published maps and institutional affiliations.

Open Access This article is licensed under a Creative Commons Attribution 4.0 International License, which permits use, sharing, adaptation, distribution and reproduction in any medium or format, as long as you give appropriate credit to the original author(s) and the source, provide a link to the Creative Commons license, and indicate if changes were made. The images or other third party material in this article are included in the article's Creative Commons license, unless indicated otherwise in a credit line to the material. If material is not included in the article's Creative Commons license and your intended use is not permitted by statutory regulation or exceeds the permitted use, you will need to obtain permission directly from the copyright holder. To view a copy of this license, visit http://creativecommons. org/licenses/by/4.0/.

\section{References}

Akbari, E., \& McCuaig, K. (2017). Early education report 2017. The Atkinson Centre for Society and Child Development. http:// ecereport.ca/en/.

Alexander, C., Beckman, K., MacDonald, A., Renner, C., \& Stewart, M. (2017). Ready for Life: A Socio-Economic Analysis of Early Childhood Education and Care. https://www.conferenceboard.ca/ (X(1)S(swylsbvae353i0n5wawyzasu))/e-Library/abstract. aspx?did=9231\&AspxAutoDetectCookieSupport $=1$.

Allen, A., Hancock, S. D., W. Lewis, C., \& Starker-Glass, T. (2017). Mapping Culturally Relevant Pedagogy into Teacher Education Programs: A Critical Framework. Teachers College Record, 119 (1), 1-26.

Amineh, R. J., \& Asl, H. D. (2015). Review of Constructivism and Social Constructivism. https://www.semanticscholar.org/paper/ Review-of-Constructivism-and-Social-Constructivism-AminehAsl/38903f4a7255496f75124d639e14e9b810c17370.

Archambault, J., Côté, D., \& Raynault, M.-F. (2020). Early childhood education and care access for children from disadvantaged backgrounds: Using a framework to guide intervention. Early Childhood Education Journal, 48(3), 345-352. https://doi.org/10. 1007/s10643-019-01002-x.

Baker, F. S. (2014). Tensions in Policy and Practice: Influences on Play in Abu Dhabi's New School Model KG Framework. Early Child Development and Care, 184(12), 1830-1842. eric.

Barbarin, O. A., McCandies, T., Early, D., Clifford, R. M., Bryant, D., Burchinal, M., Howes, C., \& Pianta, R. (2006). Quality of Prekindergarten: What families are looking for in public sponsored programs. Early Education and Development, 17(4), 619-642. https://doi.org/10.1207/s15566935eed1704_6.
Battiste, M. (2008). The decolonization of aboriginal education: Dialogue, reflection, and action in Canada in Educational theories and practices from the majority world (pp. 168-195). https://doi. org/10.4135/9788132100683.n8.

Bennett, J. (2008). Early Childhood Services in the OECD Countries: Review of the literature and current policy in the early childhood field. Innocenti Research Centre, UNICEF. https://www.unicefirc.org/publications/502/.

Bigras, N., Bouchard, C., Cantin, G., Brunson, L., Coutu, S., Lemay, L., Tremblay, M., Japel, C. \& Charron, A. (2010). A comparative study of structural and process quality in center-based and familybased child care services. Child \& Youth Care Forum, 39(3), 129-150. https://doi.org/10.1007/s10566-009-9088-4.

Blackmore, R., Aylward, E., \& Grace, R. (2016). "One of the kids": Parent perceptions of the developmental advantages arising from inclusion in mainstream early childhood education services. Australasian Journal of Early Childhood, 41(2), 13-17. https:// doi.org/10.1177/183693911604100203.

Braun, V., \& Clarke, V. (2006). Using thematic analysis in psychology. Qualitative Research in Psychology, 3(2), 77-101. https:// doi.org/10.1191/1478088706qp063oa.

Campbell, F., Pan, Y., \& Burchinal, M. (2019). Sustaining Gains from Early Childhood Intervention: The Abecedarian Program. In A. Reynolds \& J. Temple (Eds.), Sustaining early childhood learning gains: Program, school, and family influences (pp. 268-286). Sustaining Gains from Early Childhood Intervention: The Abecedarian Program. https://www.cambridge.org/core/ books/sustaining-early-childhood-learning-gains/sustaining-ga ins-from-early-childhood-intervention-the-abecedarian-program/ F3371034EB6D69B9778DBFB0C57D08CD.

Carolan, P.L., McIsaac, J-L.D., Richard, B., Turner, J., \& McLean, C. (2019). Families' Experiences of a Universal Play-based Early Childhood Program in Nova Scotia: Implications for Policy and Practice. Journal of Research in Childhood Education, 35 (4):550-566. https://doi.org/10.1080/02568543.2020.1773588.

Charlton, P., Azar, R., Luke, A., Doucet, S., Montelpare, W., Nagel, D., Hyndman, N., \& Thompson, K. (2017). Falling Through the Cracks: Barriers to Accessing Services for Children with Complex Health Conditions and their Families in New Brunswick. Journal of New Brunswick Studies 8, 26.

Corter, C., \& Pelletier, J. (2010). Schools as integrated service hubs for young children and families: Policy Implications of the Toronto First Duty Project. International Journal of Child Care and Education Policy, 4(2), 45-54. https://doi.org/10.1007/2288-6729-4-2-45.

Dahlberg, G., Moss, P., \& Pence, A. (2013). Beyond Quality in Early Childhood Education and Care: Languages of evaluation. Routledge. https://doi.org/10.4324/9780203371114.

Department of Education and Early Childhood Development. (2018). Capable, Confident, and Curious: Nova Scotia's Early Learning Curriculumn Framework. https://www.ednet.ns.ca/docs/ nselcurriculumframework.pdf.

Dodd-Nufrio, A. T. (2011). Reggio Emilia, Maria Montessori, and John Dewey: Dispelling Teachers' Misconceptions and Understanding Theoretical Foundations. Early Childhood Education Journal, 39 (4), 235-237. https://doi.org/10.1007/s10643-011-0451-3.

Eisazadeh, N., Rajendram, S., Portier, C., \& Peterson, S. S. (2017). Indigenous children's use of language during play in rural Northern Canadian kindergarten classrooms. Literacy Research: Theory, Method, and Practice, 66(1), 293-308. https://doi.org/10. 1177/2381336917719684.

Fisher, K. R., Hirsh-Pasek, K., Newcombe, N., \& Golinkoff, R. M. (2013). Taking shape: Supporting preschoolers' acquisition of geometric knowledge through guided play. Child Development, 84(6), 1872-1878. https://doi.org/10.1111/cdev.12091.

Frank, L., \& Fisher, L. (2020). 2019 Report Card on Child and Family Poverty. Canadian Centre for Policy Alternatives. https://www. 
policyalternatives.ca/sites/default/files/uploads/publications/Nova $\% 20$ Scotia\%20Office/2020/01/2019\%20report\%20card\%20on\% 20child\%20and\%20family\%20poverty.pdf.

Graham, K., \& Underwood, K. (2012). The reality of rurality: Rural parents' experiences of early years services. Health \& Place, 18(6), 1231-1239. https://doi.org/10.1016/j.healthplace.2012.09.006.

Japel, C., \& Friendly, M. (2019). Inequalities in Access to Early Childhood Education and Care in Canada (Expert Report No. 4; ICEC Working Paper Series, p. 76). International Centre on Early Childhood Education and Care.

Kane, N. (2016). The Play-Learning Binary: U.S. Parents' Perceptions on Preschool Play in a Neoliberal Age. Children \& Society, 30(4), 290-301. https://doi.org/10.1111/chso.12140.

Kirova, A., Pacinii-Ketchabaw, V., \& Prochner. (2013). Children's representation of cultural scripts in play. In Resituating Canadian Early Childhood Education. Peter Lang Publishing.

Komro, K. A., Burris, S., \& Wagenaar, A. C. (2014). Social determinants of child health: Concepts and measures for future research. Health Behavior and Policy Review, 1(6), 432-445. https://doi.org/10.14485/HBPR.1.6.1.

Lee, S., \& Goh, G. (2012). Action Research to Address the Transition from Kindergarten to Primary School: Children's Authentic Learning, Construction Play, and Pretend Play. Early Childhood Research \& Practice, 14(1) n1.

Lin, H.-C., \& Dunnett, A. J. (2018). An exploration of parental preferences for child care services in Canada. Services Marketing Quarterly, 39 (1), 49-63. https://doi.org/10.1080/15332969.2017.1398028.

MacDonald, D. (2018). Child Care Deserts in Canada. Canadian Centre for Policy Alternatives. https://www.policyalternatives.ca/ sites/default/files/uploads/publications/National\%20Office/2018/ 06/Child\%20Care\%20Deserts.pdf.

Maggi, S., Irwin, L. J., Siddiqi, A., \& Hertzman, C. (2010). The social determinants of early child development: An overview: Early child development. Journal of Paediatrics and Child Health, 46(11), 627-635. https://doi.org/10.1111/j.1440-1754.2010.01817.x.

Magnuson, K., \& Shager, H. (2010). Early education: Progress and promise for children from low-income families. Children and Youth Services Review, 32(9), 1186-1198. https://doi.org/10. 1016/j.childyouth.2010.03.006.

Malsch, A. M., Green, B. L., \& Kothari, B. H. (2011). Understanding parents' perspectives on the transition to Kindergarten: What early childhood settings and schools can do for at-risk families. Best Practice in Mental Health, 7(1), 47-66.

Masten, A. S., Cutuli, J. J., Herbers, J. E., \& Reed, M.-G. J. (2009). Resilience in development. The Oxford Handbook of Positive Psychology. https://doi.org/10.1093/oxfordhb/9780195187243.013.0012.

Matei, A., \& Ghenta, M. (2018). Quality of the ECEC Workforce in Romania: Empirical evidence from parents' experiences. $E d u$ cation Sciences, 8, 2.

McCain, H. M. N., Mustard, J. F., \& Shanker, S. (2007). Early Years Study 2: Putting Science into Action. Council for Early Child Development.

Melhuish, E., Quinn, L., Sylva, K., Sammons, P., Siraj-Blatchford, I., \& Taggart, B. (2013). Preschool affects longer term literacy and numeracy: Results from a general population longitudinal study in Northern Ireland. School Effectiveness and School Improvement, 24 (2), 234-250. https://doi.org/10.1080/09243453.2012.749796.

Milne, J., \& Oberle, K. (2005). Enhancing rigor in qualitative description. Journal of Wound, Ostomy and Continence Nursing, 32(6), 413-420. https://doi.org/10.1097/00152192-200511000-00014.

Neergaard, M. A., Olesen, F., Andersen, R. S., \& Sondergaard, J. (2009). Qualitative description - the poor cousin of health research? BMC Medical Research Methodology, 9(1), 52 https:// doi.org/10.1186/1471-2288-9-52.

Noble, K. (2007). Parent choice of early childhood education and care services. Australian Journal of Early Childhood. 32(2), 51-57.
Nova Scotia Department of Education and Early Child Development. (2017). Pre-Primary Program. https://www.ednet.ns.ca/preprimary-program.

Pelletier, J., \& Corter, C. (2005). Toronto First Duty: Integrating kindergarten, childcare, and parenting support to help diverse families connect to schools. Multicultural Education, 13(2), 30-37.

Peterson, S. S., \& Horton, L. (2019). Child-directed dramatic play as identity text in Northern Canadian indigenous kindergarten classrooms. Literacy, 53(4), 254-264. https://doi.org/10.1111/lit.12174.

Preston, J. P., Cottrell, M., Pelletier, T. R., \& Pearce, J. V. (2012). Aboriginal early childhood education in Canada: Issues of context. Journal of Early Childhood Research, 10(1), 3-18.

Sackes, M. (2013). Priorities for developmental areas in early childhood education: a comparison of parents' and teachers' priorities. Educational Sciences: Theory and Practice, 13(3), 1684-1690. https://doi.org/10.12738/estp.2013.3.1634.

Saluja, G., Early, D. M., \& Clifford, R. M. (2002). Demographic characteristics of early childhood teachers and structural elements of early care and education in the United States. Early Childhood Research \& Practice, 4(1). https://eric.ed.gov/?id=ED464765.

Sandelowski, M. (2009). What's in a name? Qualitative description revisited. Research in Nursing \& Health, n/a-n/a. https://doi.org/ 10.1002/nur.20362.

Savigny, M. (2017). Increasing Access to Early Childhood Education and Care in Canada: The Case for a More Equitable System for Canadians Under 5. /paper/Increasing-Access-to-EarlyChildhood-Education-and-Savigny/6283347c64f6912e7fba52ca 629521f8ca17e31d.

Scopelliti, M., \& Musatti, T. (2013). Parents' view of child care quality: Values, evaluations, and satisfaction. Journal of Child \& Family Studies, 22(8), 1025-1038. https://doi.org/10.1007/ s10826-012-9664-3.

Scotland, P. (2017). A community survey of child care issues in Canadian shift workers: Evidence for barriers and opportunities. International Journal of Child, Youth and Family Studies, 8(1), 42 https://doi.org/10.18357/ijcyfs81201716741.

Shlay, A. B., Weinraub, M., Harmon, M., \& Tran, H. (2004). Barriers to subsidies: Why low-income families do not use child care subsidies. Social Science Research, 33(1), 134-157. https://doi. org/10.1016/S0049-089X(03)00042-5.

Singh, P., \& Zhang, K. C. (2018). Parents' perspective on early childhood education in New Zealand: Voices from Pacifika families. Australasian Journal of Early Childhood, 43(1), 52-58.

Siraj, I., Kingston, D., Neilsen-Hewett, C., Howard, S., Melhuish, E., Rosnay, M. de, Duursma, E., \& Luu, B. (2016). Fostering effective early learning: A review of the current international evidence considering quality in early childhood education and care programmes - in delivery, pedagogy and child outcomes. Faculty of Social Sciences - Papers (Archive). https://ro.uow.edu. au/sspapers/4287.

Sollars, V. (2017). Parents' expectations about early years services. Early Years, 37(3), 285-299. https://doi.org/10.1080/09575146. 2016.1154507.

Sollars, V. (2020). Defining quality in early childhood education: Parents' perspectives. European Early Childhood Education Research Journal, 28(3), 319-331. https://doi.org/10.1080/ 1350293X.2020.1755488.

Statistics Canada. (2019). Survey on Early Learning and Child Care Arrangements. Government of Canada. https://www150.statcan. gc.ca/n1/en/daily-quotidien/190410/dq190410a-eng.pdf?st= elWEDFHp.

Stipek, D. J., Feiler, R., Byler, P., Ryan, R., Milburn, S., \& Salmon, J. M. (1998). Good beginnings: What difference does the program make in preparing young children for school? Journal of Applied Developmental Psychology, 19(1), 41-66. https://doi.org/10. 1016/S0193-3973(99)80027-6. 
Sylva, K., Sammons, P., Chan, L., Melhuish, E., Siraj-Blatchford, I., \& Taggart, B. (2013). The effects of early experiences at home and pre-school on gains in English and mathematics in primary school: A multilevel study in England. Faculty of Social Sciences - Papers (Archive), 277-301. https://doi.org/10.1007/s11618-013-0364-6.

Ulferts, H., Wolf, K. M., \& Anders, Y. (2019). Impact of process quality in early childhood education and care on academic outcomes: Longitudinal meta-analysis. Child Development, 90(5), 1474-1489. https://doi.org/10.1111/cdev.13296.

Underwood, K., \& Killoran, I. (2012). Parent and family perception of engagement: Lessons from early years programs and supports. Canadian Journal of Education, 35(4), 376-414.
Weisberg, D. S., Zosh, J. M., Hirsh-Pasek, K., \& Golinkoff, R. M. (2013). Talking It Up: Play, Language. Development, and the Role of Adult Support. American Journal of Play, 6(1), 39-54.

Willis, D. G., Sullivan-Bolyai, S., Knafl, K., \& Cohen, M. Z. (2016). Distinguishing features and similarities between descriptive phenomenological and qualitative description research. Western Journal of Nursing Research, 38(9), 1185-1204. https://doi.org/ 10.1177/0193945916645499.

Yahya, R. (2016). Bridging home and school: understanding immigrant mothers' cultural capital and concerns about play-based learning. Early Years: An International Journal of Research and Development, 36(4), 340-352. 